\title{
RULE PROLIFERATION AND INSTITUTIONAL QUALITY IN THE ENTERPRISE BANKRUPTCY LAW OF THE PEOPLE'S REPUBLIC OF CHINA, 1986-2009
}

\author{
Nathan Betancourt and Barbara Krug*
}

\begin{abstract}
Does an increase in the quantity of legal rules influence the overall quality of the formal institution to which they belong? In this article, we draw upon a longitudinal analysis of the People's Republic of China's Enterprise Bankruptcy Law in order to answer this question. We aim to examine the degree to which the proliferation of legal provisions, as opposed to the elaboration of the statute, affects organisational compliance with the law. In doing this, we find that when the expansion of the law leads to rule accretion in the absence of rule refinement, the use of the bankruptcy law by private organisations diminishes.
\end{abstract}

Keywords: institutional change; bankruptcy; China

\section{Introduction}

Rules produce rules, or more accurately, the codified provisions of a statute tend to multiply over time. ${ }^{1}$ Yet, although laws are often treated as formal, or even parchment institutions, whether alteration of the actual rules that make up this institution in aggregate affect, or change, the institution itself is a matter of some debate. ${ }^{2}$ On the one hand, an increase in the number of rules may indicate a process of ongoing refinement, or that the formal institution is keeping pace with its environment. ${ }^{3}$ However, on the other hand, rule accretion may increase the complexity of the formal apparatus surrounding the institution, which in turn increases the informational and effort based costs of compliance with a rule. ${ }^{4}$ Given this tension, can it be said that an increase in the quantity of legal rules influences the overall quality of the formal institution to which they belong?

This article encompasses an in-depth longitudinal analysis of the People's Republic of China's (PRC) Enterprise Bankruptcy Law (EBL) and empirically models the generation and elaboration of its legal provisions. The influence of both types of rule proliferation upon the organisational use of the EBL will be examined. When the number of rules increases yet the refinement of the institution does not co-occur, then the use of the bankruptcy law by private organisations drops. The proliferation of legal rules in the absence of legal rule refinement is the type of institutional instability that undermines organisational compliance with the law.

The study of the relationship between the development of legal rules and formal institutional quality contributes to an emerging body of research into legal systems in developing economies. The legal rules of developing nations vary considerably in terms of their quality, effectiveness, and survival. ${ }^{5}$ This study allows for further examination

\footnotetext{
Both authors are affiliated with the Rotterdam School of Management, Erasmus University Rotterdam, PO Box 1738, 3000 DR, Rotterdam, The Netherlands, nbetancourt@rsm.nl, bkrug@rsm.nl.

J.B. Ruhl and J. Salzman, 'Mozart and the Red Queen: The Problem of Regulatory Accretion in the Administrative State', 91 Georgetown Law Journal 4, at 757 (2003).

A. Niblett, R.A. Posner, \& A. Shleifer, 'The Evolution of a Legal Rule', 39 Journal of Legal Studies 2, at 325-327 (2010).

P.D. Jennings, M. Schulz, D.L. Patient, C. Gravel, \& K. Yuan, 'Weber and Legal Rule Evolution: The Closing of the Iron Cage?', 26 Organization Studies 4, at 621-622 (2005).

See Ruhl and Salzman, above n. 1, at 763.

S. Levitsky and M. Murrillo, 'Variation in Institutional Strength', 12 Annual Review of Political Science, at 115-117 (2009).
} 
of the degree to which this variation may arise from endogenous processes, such as an increase in legal rule quantity necessitated by the growing complexity of these nations' economies.

More specifically, this analysis contributes to a growing knowledge concerning legal reform in China. Since 1978, the issues and conflicts arising from the economic reform process have had a positive influence on the development of a national legal infrastructure, leading to a proliferation in the number of substantive legal frameworks. ${ }^{6}$ Yet an increase in simply the amount of law written in the books does not necessarily equate to an improvement in the quality of China's formal legal institutions. Adopting new rules in an effort to solve problems of organisational non-compliance may only foster further non-compliance. Since rule proliferation is inevitable, rule-makers must focus on the refinement of rules, as opposed to the blanket generation of new rules.

This paper will be set out as follows. First, the theoretical logic will be explained, followed by an overview of the PRC Bankruptcy law and the statistical model. It will then conclude with a discussion of the results and a reflection upon future research.

\section{The Development of Formal Institutions}

\subsection{Determining the Quality of Formal Institutions}

The economic approach to the design and operation of legal systems tends to be prescriptive. The operation of legal rules that possess an economic function is often judged in terms of the rules' ability to secure a certain outcome, such as aligning the interests of organisations or improving resource allocation. ${ }^{7}$ From this perspective, the effectiveness of a law is an indication of its quality. However, whilst assessing the law's impact on the regulated market segment is the most direct means of measuring its effectiveness, the result is not always quantifiable, and rarely accounts for the effect of the substantive content of the law. ${ }^{8}$ Certain attributes of the legal system, such as the capacity and influence of the legal organisation, meaning the government agency or court charged with implementing and enforcing the law, may also play a role in determining effectiveness.

In order to avoid these difficulties, this article employs an alternative benchmarking method, through which the effectiveness of a formal institution is determined by its ability to engage with the organisational community which is regulated by its provisions. If a formal institution is able to 'take root and generate shared behavioural expectations', then this alternative indicator of effectiveness may be seen as a proxy for the quality of the substantive content of the institution. ${ }^{10}$ If organisations possess some agency in their decision to employ a legal provision, then one measure of the quality of these provisions lies in their ability to attract these organisations to the formal institution or to encourage the use of the formal institution.

Yet in order for a formal institution to sustain the interest of its regulated population, it must evolve in a coherent fashion with the problem that it seeks to address. New rules arise as a response to legal lacunae, or gaps in the law, that become apparent over time.

\footnotetext{
Z. Chen, 'Capital Markets and Legal Development: The China case',14 China Economic Review 4, at 451-455 (2003); R. Peerenboom, China's Long March Towards Rule of Law (2002), at 1-6.

R.C. Ellickson, 'A Critique of Economic and Sociological Theories of Social Control', 16 Yale Law School Faculty Scholarship Series 1 (1987). Ellickson argued that a Hobbesian focus on the legal system as the source of social order lends itself to the prescriptive approach, as laws may be judged by whether they are able to lead to order.

8 R.A. Posner, Economic Analysis of Law (1979).

9 See Levitsky and Murillo, above n. 5, at 116.

10 One issue with this method is that it does not directly address whether organisations are attracted to the employment of a formal institution as a result of its implementation or its substantive content. From a signaling perspective, it may be that the substantive content of a formal institution garners more attention than the reputation of an individual agent. See T.G. Pollock and R. Gulati, 'Standing out from the Crowd: The Visibility Enhancing Effects of IPO Related Signals on Alliance Formation by Entrepreneurial Firms', 5 Strategic Organization 4, at 343 (2007) for a discussion of the conditions under which offer characteristics are capable of drawing more attention from organisational decision makers than actor characteristics.
} 
This process gives birth to the central proposition of the article, namely that changes in the quantity of formal rules may influence the quality of the formal institution they sustain. As the number of rules increases, the effort and information required to comply with them increases as well. ${ }^{11}$ Research has shown that there is not a direct correlation between an increase in the number of rules and an increase in the effort needed to comply. Rather, if the number of extant rules increases the effort required to both implement and comply with the rule more than doubles. ${ }^{12}$

However, the birth of new legal rules should also have a positive effect on the quality of the legal institution. The refinement of a legal rule (through the creation of new rules) should enhance its stability and lead to increased compliance on the part of organisations. New rules 'unify and systematize existing rules and law' and may have a positive effect on the 'clarity' and 'orderliness' of the law. ${ }^{13}$ Since understanding and applying laws is not a cost-free exercise, firms that are attracted to a specific law, due to the manner in which that legal rule incentives economic behaviour, are not likely to abandon that law. This discussion of the possible consequences of rule proliferation details the possible effects of an increase in the quantity of rules upon the quality of a formal institution.

\subsection{Rule Accretion}

We will firstly examine the manner in which legal rules increase over time. Drawing upon Weber's view of law, we endorse a rules breed rules dynamic, or the view that the presence of rules leads to the generation of further rules. ${ }^{14}$ More precisely, legal professionals, judges and lawyers who interpret the law while applying it to a case wield considerable influence over the proliferation of a rule. ${ }^{15}$ The judicial interpretation of a rule acts as a signal of either high or low quality, usefulness or troublesomeness. The result may attract the attention of lawmakers, who may seek to modify the rule. ${ }^{16}$

Although this interpretation may hold in common law systems, it requires some modification in order to apply to civil law jurisdictions, such as China. ${ }^{17}$ In such circumstances, instead of the legal profession being the sole signaling agent, regulators or administrators of state agencies, working in conjunction with the organisations that make use of the law, also act as signaling agents. ${ }^{18}$ One result of this agentic signaling is the facilitation of the identification of legal lacunae, or areas for which the law does not provide solutions. This suggests that the rules breed rules dynamic may be even stronger in civil law systems than in common law systems. Given the foregoing, these mechanisms suggest the first hypothesis:

HYPOTHESIS 1: The total number of legal rules present in a body of law has a positive effect on the likelihood of the birth of a new rule.

\subsection{Rule Refinement}

In transition economies, where bankruptcy was unknown during the socialist past, the integration of insolvency law into the unfolding private economic framework requires some degree of patience. While the quality of the first output of bankruptcy law in a transition economy may be poor in comparison to the quality of bankruptcy law in

1 See Ruhl and Salzman, above n. 1, at 763.

12 Id., at 766-767.

13 M. Schulz, 'Limits to Bureaucratic Growth: The Density Dependence of Organizational Rule Births', 43 Administrative Science Quarterly 4, at 851 (1998); M. Weber, Economy and Society (1968; 1921), at 848

14 M. Weber, The Theory of Social and Economic Organization (1947; 1921); 'Weber argued that rules should proliferate as part of the progressive rationalization of law', Jennings et al., above n. 3, at 631.

15 Id.

16 See Jennings et al., above n. 3, at 629.

17 See Peerenboom, above n. 6, at 1-6.

18 X. Zhang, L. Ortolano, \& Z. Lu, 'Agency Empowerment through Administrative Litigation Law: Court Enforcement of Pollution Levels in Hubei Province', 202 The China Quarterly, at 307-326 (2010). 
developed countries, over time the bankruptcy law should develop towards market conforming legislation, which will aid the integration of the institution into the economy. The early versions of the bankruptcy law are testament to the fact that this legislation was not market conforming but rather, was pointed towards the iron rice bowl.$^{19}$ From 1949 to 1979, the purpose of a firm was to provide for its workers; when this perspective was applied to bankruptcy, it meant that the firm was obliged to look after its workers' interests before satisfying their creditor. Hence, the image of the iron rice bowl, the cradling of the worker from birth to grave within the commercial apparatus of the state. For the bankruptcy law to be effective within China, it would need to be refined, moving away from a non-market orientation towards a market friendly approach.

In any bankruptcy regime, the issue of whether the law is oriented towards the creditor (creditor friendly) or the debtor (debtor friendly) is very important, as research suggests that debtor friendly regimes have system beneficial outcomes in jurisdictions such as China, where a high level of entrepreneurship ensures quick re-engagement of resources. ${ }^{20}$ Given the high level of uncertainty and entrepreneurship in the competitive business environment that dominates in China, this suggests that refinement towards market orientation would reflect a debtor friendly approach, in which new rules are generated that protect the assets of a firm and allow the management to correct mistakes. This gives rise to the second hypothesis:

HYPOTHESIS 2: The rate of generation of new rules increases with the presence of debtor friendly provisions.

\subsection{Distinguishing Proliferation from Refinement}

The above hypotheses, whilst suggesting that legal rules will proliferate over time, do not distinguish between accretion and refinement, but rather point to their simultaneous occurrence within a formal institution. In order to ascertain which dynamic is influencing the quality of the formal institution, the effect of both proliferation and refinement upon the rate of organisations declaring bankruptcy is examined.

Research into regulatory accretion has found that the most effective strategy for dealing with the increasing information burden that arises with new rules is to expand the resource base necessary for rule interpretation. ${ }^{21}$ This expansion of an individual firm's resource base will arise if the newly enacted provisions represent a refinement of organisation friendly provisions. As a result, the growth of new legal provisions should have a positive effect on the number of firms declaring bankruptcy. However, if the newly generated rules are unfriendly to organisations, then the growth of new rules should have a negative effect on the number of firms declaring bankruptcy. Therefore, we suggest a third hypothesis:

HYPOTHESIS 3: The number of firms declaring bankruptcy will decrease with the growth of rules if the generated rules are not debtor friendly.

\section{Enterprise Bankruptcy Law}

Two foundational texts mark the starting point of the formal institution of bankruptcy within China. The National People's Congress promulgated the Law of the People's Republic of China on Enterprise Bankruptcy on 2 December 1986, which came into operation on 1 October 1988..$^{22}$ On 9 April 1991, the PRC's Civil Procedure Law (CPL) was approved; Chapter XIX of the CPL deepened and expanded the previous text, and

\footnotetext{
C. Booth, 'The 2006 PRC Enterprise Bankruptcy Law: The Wait Is Finally over', 20 Singapore Academy of Law Journal, at 284 (2008).

20 J.E. Stiglitz, 'Whither Reform? Ten Years of Transition', 7 Voprosy Economiki (1999).

21 See Ruhl and Salzman, above n. 1, at 763.

22 Law of the People's Republic of China on Enterprise Bankruptcy (Trial Implementation) (2 December 1986) ("1986 Chinese Bankruptcy Law"), translated in Legislative Affairs Commission of the Standing
} 
addressed the application of the bankruptcy law to private enterprises, or non-state owned enterprises (SOE) ${ }^{23}$ From 1991 to 2006, all further laws on bankruptcy represent the further promulgation and possible refinement of the concepts set out in these two texts.

These laws were quite short. The 1986 Chinese Bankruptcy Law consisted of 43 articles, while Chapter XIX of the CPL consisted of eight articles. ${ }^{24}$ As a result, the language used was both broad and ambiguous. Insufficient space was allocated for the detailing of important procedures. Chapter XIX failed to specify whether non-SOEs were subject to the provisions of the 1986 Law; in addition, the 1986 law did not establish a priority order for creditors. ${ }^{25}$ To address this issue, the Supreme People's Court issued a number of opinions interpreting both laws. ${ }^{26}$

The first of these, the 1991 Supreme People's Court Opinion, consisting of 76 articles, interpreted the 1986 Chinese Bankruptcy Law. It attempted to clarify issues relating to precedence, such as whether workers' rights were given precedence over creditors' rights in bankruptcy. A significant issue was the applicability of provisions in the 1986 Bankruptcy law for SOEs to non-SOEs. The ambiguity of the law was such that organisations did not know which articles of a given law to apply when declaring bankruptcy. In addition, Article 189 of the PRC's Company Law supplemented the provisions of the 1991 PRC's CPL. ${ }^{27}$

Despite this significant clarification, use of the law was low. From 1989 to 1993 , the court accepted only 1,153 cases in total, an average of 191 a year. ${ }^{28}$ It has been estimated that prior to 1996, over 8 million enterprises existed in China, and that almost half of these enterprises operated at a loss. ${ }^{29}$ A national survey conducted in 1997 of 14,923 SOEs found that $40.5 \%$ were estimated to be losing money, yet the rate of firms declaring bankruptcy was not increasing. ${ }^{30}$ Dissatisfaction with this low effectiveness led to two outcomes. Firstly, the state began to consider issuing a revised bankruptcy code. Secondly, the State Council issued several Bankruptcy Policy Decrees. ${ }^{31}$ These decrees applied to selected SOEs regardless of whether the 1986 Bankruptcy law applied..$^{32}$ The decrees extended the reach of the 1986 law while simultaneously superseding the law; companies would file under the 1986 law but refer to the decrees in doing so.

These decrees were issued in order to facilitate debt restructuring through mergers and acquisitions and bankruptcy filings under the Capital Structure Optimization Program (CSOP). ${ }^{33}$ For example, on 25 October 1994, the State Council issued a notice that addressed problems involving the resettlement of workers of state owned industrial enterprises. $^{34}$ The notice provided special treatment for the resettlement of workers; resettlement rights were given first priority when funds from the sale of assets, such as land use rights of the bankrupt SOE were distributed.

In 2006, the PRC's Enterprise Bankruptcy law harmonised the various insolvency processes in China and enacted a unified law that replaced the old patchwork of

Commission of the National People's Congress (compilation), Laws of the People's Republic of China (Civil and Commercial Laws 289-297) (1983-1986).

23 PRC Civil Procedure Law, promulgated by Order No 44 of the President of the PRC on 9 April 1991 and effective as of that date.

24 See Booth, above n. 19, at 277.

25 Id.

26 Opinion on Questions Concerning the PRC Enterprise Insolvency Law, Ref No 2500/91.0.07. Printed in the Research Office of the Supreme People's Court (compilation), The Assemblage of Judicial Interpretations of the Supreme People's Court of the PRC ("1991 PRC Supreme People's Court Opinion").

${ }_{27}$ W. Wang and C. Booth 'Study on Alternative Approaches for Debt Restructuring of Enterprises in China' (2002) World Bank Report for the State Economy and Trade Commission of China, World Bank, at 12 .

28 X. Zhang and C. Booth 'Beijing's Initiative on Cross-Border Insolvency: Reflections on a Recent Visit of Hong Kong Professionals to Beijing', 10 American Bankruptcy Institute Law Review, at 29-39 (2002).

29 Id.

30 Id.

31 See Booth, above n. 19, at 280

32 Id., at 279-280.

33 See Wang and Booth, above n. 27. At 8-16.

34 State Council of the People's Republic of China, Proposal for Carrying Out State-Owned Enterprise Bankruptcy Law in Some Cities, Document No. 59 (1994). 
insolvency legislation. ${ }^{35}$ Major innovations in the new law included the replacement of the liquidation committee as the overseer of the bankruptcy process with administrators. ${ }^{36}$ This change was meant to address a gap in control; the liquidation committee was formed 15 days after the court has determined that a firm meets the requirements of the law and not when the firm declared bankruptcy. In addition to rules concerning administrators, the 2006 Enterprise Bankruptcy Law also addressed corporate reorganisation, a process that was technically permitted under the old law, but never used. ${ }^{37}$ Under the new law, both debtors and creditors may apply for reorganisation, meaning that a creditor may apply for the bankruptcy of a debtor, and vice versa. ${ }^{38}$

\subsection{Unit of Measurement}

Laws can be categorised according to their legal status (i.e. the position a law has in a legal system's hierarchy). In general, national laws are ranked higher than local laws. If a regulation embedded in a local law (defined as a law passed by a municipal or state legislature) contradicts a provision embedded in the national law, the national rule supersedes the local rule. In addition, laws are time sensitive; if two national rules have contradicting positions concerning the same issue, the national rule promulgated at the latest point in time, or the most current rule, prevails.

Due to this hierarchy of law, this article focuses on law at the national level. In China, the legislative body (the National People's Congress) and the executive body (the State Council) have the power to promulgate laws at the national level. The judicial branch does not formally have the power to make law through the issuance of judicial precepts. Despite the authority of the State Council, this article only analyses the codified rules promulgated by the National People's Congress, for reason of the latter body's de jure rule maker status at the national level.

Since not all laws are structured in precisely the same way, only the most detailed level of analysis lends itself to proper longitudinal comparison. Our textual specific events are constructed as the combination of the occurrence of the event and the size of the event. ${ }^{39}$ Determining the size of a national regulation may be accomplished through counting either the number of sentences, or the number of characters per rule. The individual unit of measurement is the specific text of an act, a collection of national regulations created during the law making process. An act is composed of various chapters, which may be subdivided into sections, articles, and paragraphs, referred to as sub clauses. The various provisions of the act are the individual regulations, which outline the specifics of a law; these regulations occur within paragraphs. Thus, the specific text refers to a count of the number of rules and the size of these rules, as measured by the number of sentences devoted to these rules.

When comparing a rule in Chinese to a rule in English, the number of sentences per rule is highly consistent in either language; this can be contrasted with the other two methods, which show marked variation. We believe that differences in characters between the two languages cause the sentence count method to be the most reliable. During the data collection process, we monitored the layout of the printed version of the laws in both Chinese and English, and compared this layout to the downloaded versions. Although differences in terms of typeface, size, margins and line spacing did occur, the average number of sentences per page was minimally affected by these changes. In addition, when comparing counts of the number of sentences per rule in Chinese and English, the two languages strongly correlate. ${ }^{40}$

35 S. Kargman 'Solving the Insolvency Puzzle', 34 China Business Review 5, at 44-48 (2007).

36 Enterprise Insolvency Law of the People's Republic of China (1 June 2007), Translated by the Bankruptcy Law and Restructuring Research Center of the Chinese University of Politics and Law of Beijing University, 17 International Insolvency Review 1, 33-55 (2008).

37 See Booth (2008), above n. 19, at 304-306.

382007 PRC Enterprise Bankruptcy Law, Article 70.

39 A. van Witteloostuijn and G. De Jong 'Ecology of National Rule Birth: A Longitudinal Study of Dutch Higher Education Law', 20 Journal of Public Administration Research and Theory 1, at 198-199 (2010).

Please contact the author for this analysis if interested. 
Dependent Variable. We use two dependent variables in this study. For Hypotheses 1 and 2, we use the Rule Birth variable, which measures, on an annual basis, the generation of legal rules that did not previously exist in the text of the bankruptcy law. A revision of an existing rule is not counted as the birth of an entirely new rule. We distinguish between a revision and the generation of a new rule by following the law from its genesis. A revision is identified as an adjustment of a previous rule that does not supplant or render a previous rule obsolete. A rule birth event (the generation of a completely new rule) arises either through the extension of the legal domain of the EBL or through the replacement of an existing rule. When coding, two lawyers reviewed the various laws; inter-coder agreement was high, with initial coding yielding agreement in $89 \%$ of the cases. For the remaining cases, agreement was reached via discussion.

Our second dependent variable comprises of the number of total commercial bankruptcy filings from 1986 to 2009 obtained from the Chinese Statistical Yearbook. We use this variable in order to better distinguish legal rule proliferation from legal rule refinement. We include both firms that file for liquidation and reorganisation under the bankruptcy code. This measures the total use of both the bankruptcy law and the legal system. Whilst our measurement of organisational compliance does not address the degree to which firms actually follow the letter of the law, they do measure whether or not the firm places itself under the aegis of the bankruptcy law.

Independent Variables. In order to account for whether the total number of rules present in the body of law has a positive influence on the likelihood of the further generation of rules, we use the total rule birth density variable to measure the total number of rules generated within the body of law of bankruptcy in a given year. In order to examine whether the law becomes more refined over time, we use the La Porta index of creditor rights. ${ }^{41}$ Examining change in the index of creditor rights allows us to measure whether or not the quality of the law increases or decreases as the law changes. This index consists of four binary variables. The first is facilitate reorganisation, which tests for restrictions placed on firms that file for reorganisation. These restrictions may come from the government via the influence of local government upon the reorganisation process, or from the court. A value of 1 indicates that no restrictions are present. Second, No Automatic Stay on Assets refers to whether assets are automatically frozen during bankruptcy, or may be put to productive use during the bankruptcy process. A value of 1 indicates that assets are not frozen during bankruptcy. Third, Secured Creditor Priority refers to whether or not a secured creditor, meaning a creditor who has received a security interest on the loan made to a bankrupt firm, is repaid first from the sale of assets; 1 indicates that the secured creditor has priority. Fourth, Management Stay refers to whether the management is able to remain with the firm or is replaced; 1 indicates that current management remains with the firm.

Lastly, as the issue of whether the bankruptcy law has a creditor or a debtor focus is also of importance, we code for whether a regulation provides rules for creditors or for debtors. This variable is measured on a binary basis, in which a value of 1 indicates that there is a rule requiring that the creditor must perform a task during bankruptcy proceedings.

Control Variables. Each individual rule is also categorised according to its form as either a procedure or a standard. A procedure consists of a set of instructions that may be applied by an actor in a relatively mechanical fashion. A standard gives direction to a legal organisation to measure an empirical occurrence against a predetermined set of values. A common example is negligence, in which the court must determine the degree to which there has been a dereliction of duty, as opposed to whether a dereliction of duty has occurred (which would be a procedure). The standard variable measures, on a binary basis, whether a rule is a standard; a value of 1 indicates the presence of a standard.

41 R. La Porta, F. Lopez-de-Silanes, A. Shleifer, \& R.W. Vishny 'Law and Finance', 106 Journal of Political Economy, at 1126-1151 (1998). 
We also measure the length of the individual legal rules in order to control for the informational burden of a rule. As much of the negative impact of rule proliferation is linked to this burden, we control for the length of a rule in order to distinguish between the length and the amount of rules. In other words, there is a difference between a legal institution having a large number of very short rules versus the rules themselves being too long and hence containing too much information. The length of rules is a count variable, through which the number of sentences that make up a rule are counted.

In order to account for variation in the structural environment that may influence the use of law, we use a number of dummy variables to mark when China's business environment experienced a macro-economic crisis, such as the Asian Financial Crisis (1998-2000). During a crisis, more companies are forced into bankruptcy, which may account for increases in the use of law. This variable is measured on a binary basis, with 1 indicating the presence of a crisis. Similarly, we also indicate the years in which the central government forced companies into bankruptcy. From 1994 to 1998, via its Capital Structure Optimization Program, the central government forced SOEs into bankruptcy. This Central Government Push variable is measured on a binary basis, with 1 indicating that the government pushed state owned enterprises into bankruptcy during a specific year. Table 1 summarises and correlates all variables.

Table 1: Descriptive Statistics and Bivariate Correlations

\begin{tabular}{|l|l|l|l|l|l|l|l|l|l|l|l|l|l|l|}
\hline & Mean & S.D. & Min & Max & 1 & 2 & 3 & 4 & 5 & 6 & 7 & 8 & 9 & 10 \\
\hline Standard & 0.13 & 0.33 & 0 & 1 & 1 & & & & & & & & & \\
\hline Rule Length & 2.72 & 1.41 & 0 & 13 & 0.02 & 1 & & & & & & & & \\
\hline $\begin{array}{l}\text { Central Government } \\
\text { Push }\end{array}$ & 0.18 & 0.38 & 0 & 1 & $-0.15^{*}$ & 0.02 & 1 & & & & & & & \\
\hline $\begin{array}{l}\text { Asian Financial } \\
\text { Crises }\end{array}$ & 0.11 & 0.31 & 0 & 1 & $-0.11^{*}$ & 0.01 & $0.13^{*}$ & 1 & & & & & & \\
\hline $\begin{array}{l}\text { Total New Rule } \\
\text { Generation (Annual } \\
\text { Basis) }\end{array}$ & 38.1 & 82.16 & 0 & 262 & $0.18^{*}$ & -0.01 & $-0.21^{*}$ & $-0.16^{*}$ & 1 & & & & & \\
\hline $\begin{array}{l}\text { Facilitate } \\
\text { Reorganisation }\end{array}$ & 0.09 & 0.28 & 0 & 1 & $0.21^{*}$ & -0.02 & $-0.06^{*}$ & -0.01 & $0.07^{*}$ & 1 & & & & \\
\hline No Stay on Assets & 0.02 & 0.14 & 0 & 1 & 0.01 & 0.02 & $-0.07^{*}$ & $-0.05^{*}$ & $0.1^{*}$ & $-0.05^{*}$ & 1 & & & \\
\hline $\begin{array}{l}\text { Secured Creditor } \\
\text { Priority }\end{array}$ & 0.04 & 0.19 & 0 & 1 & 0.02 & $0.05^{*}$ & 0.01 & 0 & -0.01 & 0 & 0.03 & 1 & & \\
\hline Management Stay & 0.06 & 0.03 & 0 & 1 & $0.08^{*}$ & 0.01 & -0.01 & -0.01 & 0.02 & -0.01 & 0 & -0.01 & 1 & \\
\hline Creditor Focus & 0.08 & 0.04 & 0 & 1 & $0.04^{*}$ & $0.05^{*}$ & 0.01 & 0 & 0.01 & $0.05^{*}$ & $-0.03^{*}$ & $-0.04^{*}$ & $0.07^{*}$ & 1 \\
\hline
\end{tabular}

The asterisk indicates a $\mathrm{p}$ of less than .05 or $* \mathrm{p}<.05$.

\section{Statistical Model}

Since our data is an unbalanced panel and our dependent variable records when a legal rule is generated, we use a discrete time event-history analysis applied at the rule level to estimate the likelihood of the generation of a new rule. ${ }^{42}$ Event-history analysis models the amount of time that elapses until the event of interest occurs. Discrete time refers to the features of the time span in which the event of interest takes place. It is appropriate to use a discrete time event-history model when the time spans in the sample have been grouped into a discrete interval of time (in our case, a year). ${ }^{43}$

As the event of interest, a national rule birth, cannot occur at any point in the transition process, but rather is linked to discrete intervals in which the National People's Congress is in session, we employ a discrete time event history model. Similarly, for

42 N. Tuma and M.T. Hannan, Social Dynamics: Models and Methods (1984).

43 S.P. Jenkins, Survival Analysis (2004), Unpublished manuscript, Institute for Social and Economic Research, University of Essex. 
our alternative dependent variable, the number of firms that declare bankruptcy in a year, although the event may happen at any point throughout the year, the data on the event is banded together on an annual basis. Therefore, we also employ a discrete time framework for our second dependent variable.

Within a discrete time framework, we utilise a proportional odds, or logistic model, which is formally defined as:

$$
h, j, X .=, 1-1+\exp ,-, \alpha-j .-, \beta-{ }^{\prime} . X \text {. }
$$

This model assumes that, where $\alpha$ is a constant that is allowed to vary between the tenure segments $p$, and $\beta$ ' $\mathrm{x} t$ is a row vector of coefficients $(\beta)$ and covariates $(\mathrm{x})$, the relative odds of a new rule being generated in year $j$, given the survival of a rule up to the end of the previous year, is given by the product of two components, a relative odds common to all rules in the data set and an individual specific scaling factor. The models were estimated using the logistic regression function of the STATA statistical software package.

\subsection{Results}

The results of our event history analysis of rule birth may be found in Table 2. Model 1 in Table 2 regresses the likelihood of new rules being generated on a baseline model consisting of control variables. Model 2 adds the independent variables to this baseline model. Model 3 utilises the dependent variable of the number of organisations declaring bankruptcy and regresses the control and independent variables used for the national rule generation.

In our baseline model, the standard variable is significant and positive, indicating that, over time, new rules are more likely to be generated when an existing rule contains a standard. Research suggests that standards are more ambiguous than procedures, and give rise to further rules that fill in this ambiguity with mechanised procedures. ${ }^{44}$ In addition, the control variable for the push by the central government to force firms into bankruptcy is also positive and significant. This finding is also in line with previous research into the effect of the increased use of law upon the generation of law. In this context, the effect of forcing a higher number of firms into bankruptcy than would otherwise have declared this status had an expansive effect on the body of bankruptcy law.

Hypothesis 1 predicted a rules breed rules dynamic, or that the generation of new rules in the previous rule would have a positive effect on the future generation of legal rules. Our results in Model 2 indicate support for Hypothesis 1, showing that the total number of new rules generated on an annual basis has a significant and positive effect on the likelihood that new rules would be generated in the following year.

Hypothesis 2 predicted that rules become more refined over time or, more specifically, that the Enterprise Bankruptcy Law would move to a debtor friendly regime. Our results in Model 2 indicate support for Hypothesis 2, as the presence of rules that facilitate the reorganisation of the firm and allow the firm control of assets during bankruptcy have a positive and significant effect on the likelihood of new rule generation. Thus, the new rules that are generated are more likely to move the bankruptcy regime towards a market friendly orientation. However, rules that allow the current management of the firm to remain with the firm have a negative and significant effect on the generation of future rules, suggesting that the refinement of the EBL is at least partially incomplete.

Hypothesis 3 predicted that the number of firms declaring bankruptcy will decrease over time if the rules that are generated over time are not sufficiently debtor friendly. Using the dependant variable of the total number of firms declaring bankruptcy on an annual basis, we find support for Hypothesis 3 in Model 3. The total number of new rules generated per year has a significant negative effect on the number of firms declaring bankruptcy. Surprisingly, the standard and management stay variables have

44 K. Pistor, M. Raiser, \& S. Gelfer 'Law and Finance in Transition Economies', 8 Economics of Transition 2 , at 325-368 (2000). 
a positive effect on the number of rules declaring bankruptcy, which suggests that the presence of specific rules that do not proliferate over time may have a positive effect on the use of bankruptcy in China.

\section{Table 2: Logit Event History Model of the Likelihood of the Generation of New Rules}

\begin{tabular}{|l|l|l|l|}
\hline & Model 1 & Model 2 & Model 3 \\
\hline & Rule Birth & Rule Birth & \# Organisations declaring bankruptcy \\
\hline Control Variables & & & \\
\hline Standard & $0.53^{*}$ & 0.36 & $0.82^{* *}$ \\
\hline & $(0.19)$ & $(0.29)$ & $(0.42)$ \\
\hline Rule Length & -0.02 & -0.03 & 0.01 \\
\hline & $(0.03)$ & $(0.05)$ & $(0.04)$ \\
\hline C1: 1996-1998 & $0.69^{* *}$ & $1.25^{*}$ & 0.21 \\
\hline & $(0.30)$ & $(0.37)$ & $(0.24)$ \\
\hline C2: 1998-2000 & 0.14 & 0.7 & 0.15 \\
\hline & $(0.35)$ & $(0.42)$ & $(0.24)$ \\
\hline Independent Variables & & & \\
\hline $\begin{array}{l}\text { Total New Rule Generation } \\
\text { (Annual Basis) }\end{array}$ & & $0.02^{*}$ & $-0.01^{*}$ \\
\hline & & $(0.01)$ & $(0.01)$ \\
\hline Facilitate Reorganisation & & $0.01^{*}$ & -0.02 \\
\hline & & $(0.03)$ & $(0.03)$ \\
\hline No Stay on Assets & & $0.01^{*}$ & -0.02 \\
\hline & & $(0.04)$ & $(0.03)$ \\
\hline Secured Creditor Priority & & -0.02 & 0.18 \\
\hline & & $(0.10)$ & $(0.10)$ \\
\hline Management Stay & & $-0.10^{*}$ & $0.08^{*}$ \\
\hline & & $(0.02)$ & $(0.04)$ \\
\hline Creditor Focus & & -0.18 & 0.31 \\
\hline & & $(0.19)$ & $(0.17)$ \\
\hline Constant & & $-4.32^{*}$ & $3.45^{*}$ \\
\hline Observations & & $(0.64)$ & $(0.70)$ \\
\hline & & 3585 & 3585 \\
\hline & & & \\
\hline & & & \\
\hline & & & \\
\hline
\end{tabular}

Standard errors in parentheses: ${ }^{* *}$ significant at $5 \% ;{ }^{*}$ significant at $1 \%$.

\section{Discussion}

In order to further explore the manner in which the evolution of a legal rule will affect its effectiveness, this article utilises quantitative assessment of the patterns of legal rule evolution. While legal change remains an important topic within modern jurisprudence, there is a marked absence of quantitative studies that chart the rise or fall of formal institutions. ${ }^{45}$ Most studies of legal change examine either the effect of a specific change on a regulated population, or conceptualise legal change as an outcome that denotes change in the power and preference distributions of law-making actors. ${ }^{46}$ This paper follows an alternative route in which the endogenous properties of change within formal institutions are examined.

45 However, see Niblett et al., above n. 2, at 325.

46 See Levitsky and Murrillo, above n. 5, at 115-117. 
Whilst discussion of the design of a formal institution may lead to greater comprehension of the effect of a specific change within a legal rule, and the study of power or preference distributions among agents aids the comprehension of their incentives to change laws, examining the relevance of the inherent properties of legal rules upon legal change illustrates the constraints under which design and power distributions operate. More specifically, even when design and power distributions favour a strong formal institution, endogenous properties of the legal rule may lead to a weak legal institution that fails to produce the proper behavioural response amongst the regulated population. Thus, the study of endogenous formal institutional properties is complementary to these perspectives and sheds further light upon the conditions that may give rise to successful legal rule creation.

Despite this contribution, there are several limitations. In this case, the empirical setting may resist generalisation. Although the examination of regulatory growth is facilitated by the examination of a body of law in a transition economy, as the transition from socialism to capitalism is abetted by the generation of new legal rules, these specific conditions do not necessarily generalise outside transition economies. Similarly, China may not be the most representative transition economy given its numerous characteristic divergences from this group.

Yet all economies must deal with the generation of new rules, and studies of rule generation in the United States and Canada form the basis of the division between regulatory accretion and refinement. ${ }^{47}$ In fact, insofar as developed countries enjoy more stable legal systems, issues of legal rule proliferation and corresponding institutional weakness may be more pertinent than in transition economies. Future research should analyse the history of a body of law in a developed economy and examine conditions underlying the relationship between rule refinement and institutional effectiveness.

In conclusion, one of the challenges accompanying the study of institutions is the necessity to disentangle the endogenous characteristics that help to determine the direction and intensity of institutional change from the exogenous factors that also explain the phenomena of institutional change. This challenge is compounded in the special case of formal institutions, given the importance of design and power distributions among agents for the successful generation and institutionalisation of legal rules. Yet the law must expand regardless; thus, even in the case of well-designed laws backed by powerful groups, the determination of the type of legal expansion may lead to a better understanding of organisational compliance, or non-compliance, with the law. 